\title{
珠江三角洲城市群区域绿道与生态游頽空间 的连接度与分布模式
}

\author{
王甫园 ${ }^{1,2}$, 王开泳 ${ }^{1,2 *}$ \\ (1. 中国科学院地理科学与资源研究所, 北京 100101 ; \\ 2. 中国科学院区域可持续发展分析与模拟重点实验室,北京 100101)
}

\begin{abstract}
摘 要: 绿道对城市群构建连续的生态开放空间网络具有重要作用。基于珠三角城市群现有区域绿道网络,采用拓 扑网络和社会网络分析评估生态游㮩空间的连接度,揭示生态游㮩空间联系的空间分布模式,结果表明: “生态游 㮩空间-区域绿道”拓扑网络的 $\alpha 、 \beta 、 \gamma$ 指数分别为 $0 、 0.386 、 0.129$, 说明网络中点和边较少, 网络为树状形, 环通性不 高, 总体连接度较低; 绿道对生态游㮩空间的连接度呈集群式分布, 且处在边缘的凝聚子群连接度高于中心地区的 子群; 各集群之间的连接度呈现出东部一北部区域大于西部、东西部之间空间分割性比较明显的格局; 连接度分布 模式的形成主要受绿道政策与布局、绿道建设机制、生态游㡒空间规模集聚格局、地理阻隔与空间邻近性的影响。 最后, 论文提出了优化 “生态游息空间-绿道”分布模式、构建连接度更高的生态开放空间系统的路径, 给中国城市 群规划和发展提供参考。
\end{abstract}

关 键 词:生态游㮩空间; 绿道; 连接度;分布模式; 珠三角城市群

生态游息空间提供支持、供给、调节与文化服 务等多元生态系统服务, 是维系生态安全、提升居 民福祉的重要空间。在城市群地区, 无序扩张的建 筑设施与交通用地或难以进人的河流、山地等成为 生态游悡空间之间功能互动的阻隔, 导致生态游悡 空间分布孤岛化、破碎化。绿道是沿自然廊道(如 河流、溪谷, 或者山脊线)或交通线修建的线性绿色 开放空间,将公园、自然保护地、文化和历史场所以 及聚居区等连接起来(查尔斯 $\cdot \mathrm{E} \cdot$ 利特尔, 2013), 兼 具生态廊道、开敞空间和游径的功能, 是优化城市 群生态网络、促进区域景观整体性保护与生态空间 游㝆利用的轴线。本文试图采用地理网络分析方 法评估珠三角城市群现有绿道网络与生态游慗空 间连接的分布模式与存在的问题, 充实绿道评估的
方法, 并提出优化路径, 有利于城市群构建连续的, 融游㝆、生态与文化保护、科普教育等功能于一体 的生态开放空间骨干网。

绿道的概念由古代礼仪道、林荫道、公园道 (parkway)、带状公园、绿带、绿径(green trail)等演化 而来(Turner, 2006), 它是一种可持续利用的包含线 性要素的土地网络,经规划、设计和管理而用于生 态、游憩、文化、美学等多方面的目的, 具有线性配 置、连接、多功能性、可持续性、整合性五个特征 (Ahern, 1995)。现代意义上的绿道的实践和概念源 起于美国。19世纪时, 在城市美化运动思潮影响 下,城市公园道建设兴起, 1867 年奥姆斯特德(Frederick Law Olmsted)规划设计了一个由滨河绿色通 道连接的公园系统, 即著名的波士顿“翡翠项链”,

收稿日期: 2018-05-14; 修订日期: 2018-12-26。

基金项目: 中国博士后科学基金资助项目(2018M641457); 国家自然科学基金项目(41871151)。 [Foundation: China Postdoctoral Science Foundation, No. 2018M641457; National Natural Science Foundation of China, No. 41871151. ]

第一作者简介: 王甫园(1988-), 男, 湖南新化人,博士后, 研究方向为旅游地理与生态空间治理。

E-mail: wangfy.15b@igsnrr.ac.cn

*通信作者简介:王开泳(1980-), 男,山东滕州人,博士, 副研究员,硕士生导师,研究方向为城市地理、行政区划。

E-mail: wangky@igsnrr.ac.cn

引用格式: 王甫园, 王开泳. 2019. 珠江三角洲城市群区域绿道与生态游慤空间的连接度与分布模式 [J]. 地理科学进展, 38(3): 428-440. [Wang F Y, Wang K Y. 2019. Connectivity and distribution pattern of regional greenways and ecological recreation spaces in the Pearl River Delta urban agglomeration. Progress in Geography, 38(3): 428-440. ] DOI: 10.18306/dlkxjz.2019.03.012 
同时满足了生态保护与居民休闲需求, 并平衡了各 利益相关者的利益诉求 $($ 文克・ E・德拉姆施塔德等, 2016)。此后, Charles Eliot、Olmsted Brothers、Eliot II 和 Henry Wright 等景观设计师将绿道规划设计拓 展到大都市乃至国家尺度, 如 Charles Eliot 与 Eliot II在 19 世纪末主持的波士顿地区开放空间系统规 划利用绿道将 3 条主要河流和 6 大城市郊区开放空 间连接起来, 使波士顿地区增加了约 $630 \mathrm{~km}^{2}$ 的开 放空间(引自周年兴等, 2006; 徐东辉等, 2014)。20 世纪 60-70年代美国的环保运动进一步刺激了绿 道的研究与实践; 80 年代末, 绿道的作用受到了美 国户外游憩总统委员会的充分肯定; 至 90 年代后, 绿道运动在世界范围内扩展(周年兴等, 2006)。中 国绿道规划与建设起步较晚, 直到 2009年才在珠三 角城市群地区开始酝酿。

20 世纪 80 年代以来, 国外绿道研究集中在 4 个 方面: (1) 中外绿道发展史的研究(Fábos, 2004; Yu et $\mathrm{al}, 2006)$; (2) 绿道的规划与设计研究, 如 Linehan 等 (1995)发展了一种基于区域生物多样性保护网络的 绿道规划方法, Sinclair等(2005)基于生物多样性保 护的角度提出了绿道设计宽度要求, Toccolini 等 (2006)指出绿道的规划步骤有景观资源分析以及现 有绿道和历史游径的评价、要素综合评价、绿道网 络完善等; (3) 绿道使用行为及其影响因素研究, 如 Akpinar(2016)发现可达性影响绿道使用频率, 而绿 道的照明、安全、维护、卫生管理和停车等因素影响 绿道使用的持续时间, 又如 Senes 等(2017)发现绿道 使用人数与月份有关, 且受人口教育水平、游客人 数、历史和建筑资源的丰度和可达性的正向影响, 受小于 15 岁及大于 64 岁人口规模、城市化水平的 负向影响,还有 Keith 等(2018)发现使用者普遍关注 绿道的安全性, 使用城市绿道时追求社会互动和邻 里联系等文化利益, 而使用郊区绿道时注重自然体 验; (4) 其他研究还包括绿道的环境效应(Rao et al, 2004)以及绿道对旅游经济(Flink et al, 2001; Deenihan et al, 2013)、土地利用变化(Jang et al, 2015)的影 响。1992年, 国内期刊上出现了介绍美国绿道(greenway)的文献(叶盛东, 1992), 现有研究主要关注绿 道规划设计(刘岳等, 2012; 马向明等, 2013; 刘铮, 2017)、绿道旅游开发(胡卫华, 2013)、绿道的生态系 统服务评估(吴隽宇等, 2017)、绿道的适宜性评价 (俞孔坚等, 2005)、国外案例与经验借鉴(赵珂等, 2017)、绿道使用满意度(卢飞红等, 2015)等。
近年来,国外有关城市生态游憩空间的研究成 果相对丰富, 表现为: (1) 分析了城市生态游憩空间 对居民福祉的作用与机理 (Smyth et al, 2008; Dzhambov et al, 2015); (2) 探究了城市生态游憩空 间感知利益、使用行为及其影响因素(Madureira et al, 2015; Wan et al, 2015); (3) 探讨城市生态游唕空 间对房价与社会文化的影响及其机理(Arnberger et al, 2012; Czembrowski et al, 2016); (4) 开展城市生 态游鄎空间服务功能评价研究 (Tyrväinen 等, 2007)。此外,一些研究也考察了生态游㮩空间的 分布格局与演化(Preston-Whyte, 2001)。国内研究 成果相对较少, 主要包含 3 个方面: 基于人口需求的 城市生态游惒空间服务功能、价值评估(李华, 2015; 孙琨, 唐承财等, 2016)与配置需求(孙琨, 钟林 生等, 2016); 城市生态游憩空间的分布格局与成因 探究(李玏等, 2015); 城市生态游憩空间的感知调查 和影响因素分析(陈爽等, 2010)。总的来说, 国内外 城市群尺度生态游敀空间的直接研究较少, 相关文 献只探讨了城市群尺度生态游憩空间可达性格局 (杨丽婷等, 2016)、城市群旅游流空间结构(陈浩等, 2011)、城市群旅游合作(殷柏慧等, 2004)、欧美城市 群生态游憩空间规划经验(柴舟跃等, 2016)等。

综合来看, 当前研究对绿道与生态游憩空间连 接的分布特征与模式缺少关注, 相关分析方法的探 索也较少。连接度(connectivity)也称为连通性, 是 景观生态学的经典概念, 原意是指景观间生态流 (如物种交换)的畅通程度, 良好的连接度是促进生 态系统健康、可持续发展的关键(熊春妮等, 2008)。 生态连接度是测度景观对于生态斑块间运动的促 进或者阻碍作用程度的指标, 它主要基于渗透和图 论两大理论(富伟等, 2009)。本文借鉴生态连接度 的概念, 评价珠三角城市群以区域绿道为媒介的各 生态游胍空间连接度的分布模式,包括结构(或形 态)和功能的互动性, 并从城市群整体性的视角提 出优化路径。

\section{1 数据与方法}

\section{1 研究区域概况}

2010 年 1 月, 广东省在全国率先编制完成了 《珠江三角洲绿道网总体规划纲要》, 提出 $3 \mathrm{a}$ 内建 成总长约 $1690 \mathrm{~km}$ 的 6 条区域绿道, 分为生态型、郊 野型和都市型 3 种类型, 控制宽度分别不低于 200 、 
100、20 m(广东省住房和建设厅, 2010)。建设性规 划实际确定的绿道总里程达到 $1905.61 \mathrm{~km}$ (高长征 等, 2011)。由于地方政府建设积极性较高,到 2011 年 1 月,珠三角城市群超额建成了 $2372 \mathrm{~km}$ 的区域 (省立)绿道, 串联了 200 多个风景名胜区、自然保护 区、森林公园、郊野公园、湿地公园和历史文化遗址 遗迹等(冯利芳, 2012), 并配备了标识系统、171 个驿 站和休息点, 以及停车场、自行车租赁、餐饮、卫生、 安保等服务设施, 不仅具备生态功能, 而且也具有 生态观光、运动健身、环境教育、文化体验等多元游 馝功能。

到 2014 年 12 月底, 城市绿道、社区绿道也已经 建立起来, 珠三角城市群的绿道总长度已经达到 $8909 \mathrm{~km}$, 绿道网络逐渐完善。2016年, 广东省政府 在《政府工作报告》中提出了“修复南粤古驿道, 提 升绿道网管理和利用水平” 的工作安排, 并于 2017 年11月正式印发《广东省南粤古驿道文化线路保护 利用总体规划》, 南粤古驿道的建设, 标志着广东省 计划以历史文化线路的形式实现绿道建设的创新 及向粤东西北地区拓展(马向明等, 2017)。鉴于南 奥古驿道尚处于建设中, 且其主要分布在粤东西北 地区, 本文暂不考虑。根据规划, 区域绿道是珠三 角城市群骨干生态与游㮩综合廊道, 其地位非常重 要, 因而本文聚焦于评价区域绿道网与城市群生态
游憩空间连接的空间分布。

\section{2 数据来源与处理}

城市群生态游憩空间以城市群生态空间为基 底, 配备有基本的休闲设施, 可供居民进人开展游 㴽活动。根据重要性和价值, 将珠三角城市群区域 性的生态游憩空间界定为 7 类: 风景名胜区、森林公 园、地质公园、水利风景区、湿地公园、生态型旅游 景区以及城市公园(只含综合公园和专类公园)。前 6 类是国家自上而下指导建立的国家公园体系的重 要组成部分, 兼具生态保护与游惒服务功能, 最后 1 类也是城市重要的生态空间和公共游愳空间。并 且,一些城市将上述 7 类生态游憩空间划为游憩用 地与生态控制区(佛山市人民政府, 2017), 说明这种 界定方法具有合理性。各类生态游㮩空间的名称、 等级和面积信息的来源见表 1 。

整合各类信息并建立 Excel 数据库,且合并一 地多牌的生态游憩空间, 面积和等级数据分别取相 应类别中的较高者,最终得到 539 条生态游憩空间 记录。采用点定位和目视解译相结合的方法, 对生 态游㮩空间进行矢量化。首先, 搜集各生态游憩点 的经纬度信息,并将其导人到 ArcGIS 10.0 形成点 集矢量图层, 然后结合谷歌影像图与点的位置, 对 点周围的生态斑块进行数字化, 得到面状的生态游 憩空间。解译过程详见图 1 。

\section{表 1 生态游䡯空间属性信息的来源}

Tab.1 Sources of attribute information of ecological recreation space

\begin{tabular}{|c|c|c|}
\hline 数据 & 级别 & 来源 \\
\hline 森林公园名录 & $\begin{array}{l}\text { 国家级、省级、市 } \\
\text { 级、县(市、区)级 }\end{array}$ & $\begin{array}{l}\text { 1) 广东省森林公园一览表(https://www.gdf.gov.cn/index.php?action=view\&id=7481) } \\
\text { 2) 省级森林公园名录(https://park.gdf.gov.cn/index.php?option=com_content\&view=article\&id=79: } \\
\text { 2010-01-11-03-07-17\&catid=16:gongyuanminglu) } \\
\text { 3) 广东省免费森林公园名单(https://www.gdf.gov.cn/index.php?controller=front\&action=view\&id= } \\
\text { 10033759) } \\
\text { 4) 广东省森林公园体系和湿地公园体系建设与发展规划基础数据(https://www.gdf.gov.cn/index. } \\
\text { php?controller=front\&action=view\&id=10019383) }\end{array}$ \\
\hline $\begin{array}{l}\text { 湿地公园名录(截至 } \\
\text { 2017年7月) }\end{array}$ & $\begin{array}{l}\text { 国家级、省级、市 } \\
\text { 级、县(市、区)级 }\end{array}$ & 名称、面积和等级信息均通过申请广东省林业厅政府信息公开获得 \\
\hline 风景名胜区名录 & 国家级、省级 & $\begin{array}{l}\text { 1) 广东省风景名胜区名录(http://www.360doc.com/document/13/0122/16/9090133_261783885.shtml) } \\
\text { 2) 广东省风景名胜区体系规划(2015—2030) }\end{array}$ \\
\hline 水利风景区名录 & 国家级 & $\begin{array}{l}\text { 从水利部官方网站(http://slfjq.mwr.gov.cn/jqml/)获得国家级水利风景区名录, 其面积经由网络搜 } \\
\text { 索获得 }\end{array}$ \\
\hline 地质公园名录 & 国家级、省级 & 向广东省国土资源厅申请信息公开获得名称、面积和等级信息 \\
\hline $\begin{array}{l}\text { A 级景区名录(截至 } \\
\text { 2017年9月 } 8 \text { 日) }\end{array}$ & $5 \mathrm{~A} 、 4 \mathrm{~A} 、 3 \mathrm{~A} 、 2 \mathrm{~A}$ & $\begin{array}{l}\text { 名录和等级信息来自广东省旅游局官方网站(广东省旅游局, 2017), 面积同样通过网络搜索 } \\
\text { 整理 }\end{array}$ \\
\hline $\begin{array}{l}\text { 城市公园(综合公园 } \\
\text { 和专类公园) }\end{array}$ & $\begin{array}{l}\text { 市级, 社区公园服 } \\
\text { 务范围较小, 未予 } \\
\text { 纳人 }\end{array}$ & $\begin{array}{l}\text { 名称、位置和面积从各市园林绿化主管部门官方网站、旅游服务网站(如侠侣网)、百度百科等网 } \\
\text { 站整理,所在位置通过查询谷歌地图获得 }\end{array}$ \\
\hline
\end{tabular}

注:*由于网站较多,在正文中不便列出, 如有需要, 可联系作者获取。 

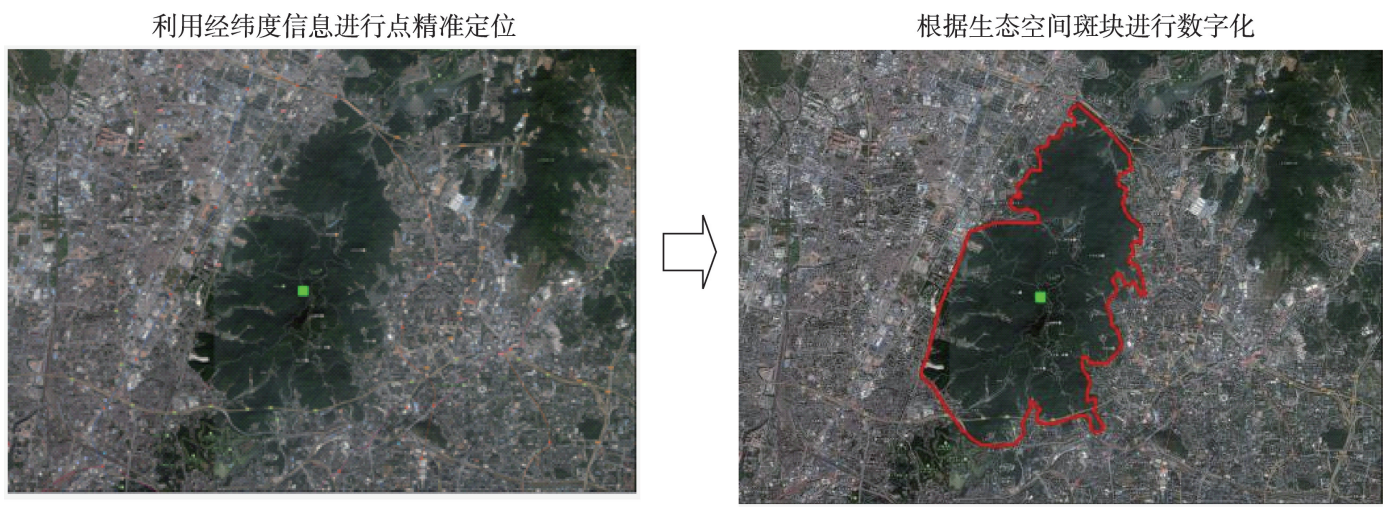

图 1 广州白云山旅游区目视解译过程示意

Fig.1 Visual interpretation process of tourist scenic spots of the Baiyun Mountain

区域(省立)绿道网矢量图层基于广东省旅游局 编制的珠三角绿道旅游地图数字化得来, 共包括 6 条区域绿道,构成珠三角城市群的绿道骨干网络。 其中广州市、佛山市和深圳市拥有的区域绿道里程 较长, 均在 $300 \mathrm{~km}$ 以上; 惠州市、东莞市和江门市的 区域绿道里程也在 $200 \mathrm{~km}$ 以上; 中山市、珠海市的区 域绿道里程较小, 分别只有 $182 、 82 \mathrm{~km}$ (图 2)。

\section{3 研究方法}

绿道和生态游㮩空间的连接关系属于典型的 地理网络, 对其分析一般采用拓扑结构测度、ArcGIS 网络分析、社会网络分析等方法, 本文综合运用 这3 种方法进行分析。

\subsection{1 生态游憩网络的拓扑结构评估}

首先定义一个 “生态游唕空间一区域绿道” 拓 扑结构网络 $N(V, L)$ (以下简称生态游㮩网络), 其中 $V$ 为节点集, 即 539 个生态游㮩空间, $L$ 为边, 即两点 之间的绿道, 边都是简单连通的, 不包含环和多重 边, 结合珠三角区域绿道旅游地图和生态游礉空间 分布图手动绘制。然后, 借鉴经济地理学的 $\alpha 、 \beta 、 \gamma$ 指数来测评 $N(V, L)$ 的网络连通性。这 3 个指数常用 于评价道路网的连通性(高洁, 2010), 适用于本研究 的情境。

其中, $\alpha$ 指数可以测度生态游憩网络出现回路 的可能性, 其表达式为(Cook, 2002):

$$
\alpha=\frac{L-V+1}{2 V-5}
$$

$\alpha$ 指网络的总体环通度, 为网络实际回路数与 可能存在的最大回路数之比; $L$ 为连接线数; $V$ 为网 络中的实际节点数。 $\alpha$ 的取值一般在 $0 \sim 1$ 之间, 但 当孤点较多,连接线较少时, 也可能存在小于 0 的情 况, 此时仍然取 0 , 表示网络中没有回路。 $\alpha$ 越接近

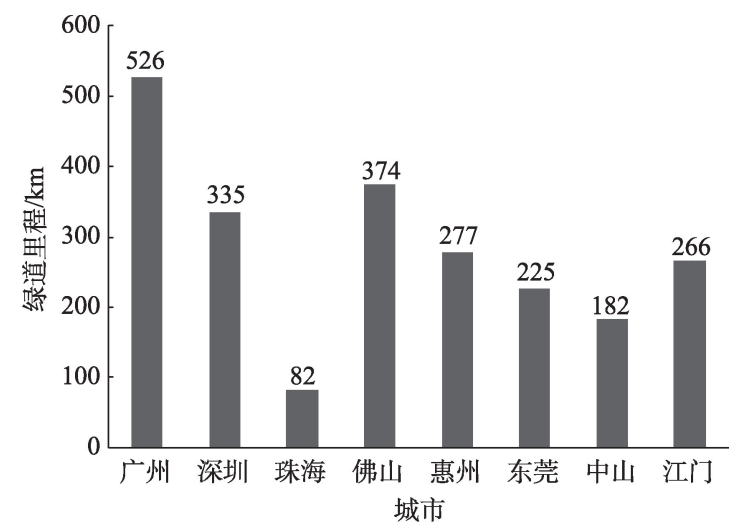

注:数据来源于高长征等(2011)。

图 2 各城市区域绿道里程

Fig.2 Total length of regional greenways in each city 1 , 说明存在的回路越多。

$\beta$ 指数又称线点率, 表示每个节点所邻接的边 的平均数目, 度量了节点与其他节点联系的难易程 度,其计算公式为:

$$
\beta=\frac{L}{V}
$$

$\beta$ 的取值范围在 $0 \sim 3$ 之间。当 $\beta=0$ 时,代表节点 之间无连接线; 当 $0<\beta<1$ 时,形成树状网络; 当 $\beta=1$ 时, 构成单一回路的网络; 当 $1<\beta \leqslant 3$ 时, 构成复杂 网络。

$\gamma$ 指数为网络的总体连接度指标, 其计算公式为:

$$
\gamma=\frac{L}{3(V-2)}
$$

$\gamma$ 的取值范围同样介于 $0 \sim 1$ 之间, 当其值为 0 时, 表示网络内没有连线; 当 $\gamma=1$ 时,表示所有节点 相互连接(高洁, 2010)。

\subsection{2 生态游憩网络的集群结构评估}

绿道连接会对生态游憩空间产生组群效应,形 成大小不一的组团。为揭示这种集群式结构,借鉴 
Linehan等(1995)的做法, 采用引力模型得出所有节 点两两之间的互动程度。一般而言, 节点的规模 (或其他质量属性) 越大, 节点间的距离越短, 节点的 互动倾向越强, 分离趋势越小。因而, 引力模型可 以反映生态游憩空间的连接度 (Linehan et al, 1995)。其计算公式为:

$$
G_{a b}=\left(N_{a} \times N_{b}\right) /\left(D_{a b}\right)^{2}
$$

式中: $G_{a b}$ 指节点 $a$ 与 $b$ 之间的互动程度; $D_{a b}$ 为两点 之间的绿道连线距离, 采用 ArcGIS 10.0 网络分析 中的 OD 成本矩阵方法测算得出; $N_{a} 、 N_{b}$ 分别指节点 $a$ 和 $b$ 的权重, 这里指每个节点的生态游㰾服务供 给水平, 为生态游唕空间等级和面积的综合值。设 定省级 (或 $4 \mathrm{~A}$ 级)生态游馝空间的质量权重为 1 , 则 县级 (或 $2 \mathrm{~A}$ 级)、地市级 (或 $3 \mathrm{~A}$ 级) 与国家级(或 $5 \mathrm{~A}$ 级) 的权重分别为 $0.333 、 0.667 、 1.333$ (表2), 将面积 乘以质量权重值就可以得出 $N$ 值。

以 $G_{a b}$ 值为指标, 采用社会网络分析 (Social Network Analysis) 中的凝聚子群分析 (Cohesive subgroup analysis)揭示生态游㮩网络的集群结构。凝 聚子群是指在社会关系网络中具有相对较强的、直 接、紧密或者经常的和积极关系的一组行动者集 合, 它可以建立在互惠关系的基础上,也可以建立 在可达性、联系频次或关系密度的基础上(Wasserman et al, 1994; 刘军, 2009)。在本文中, 凝聚子群
反映了绿道连接的生态游憩空间的小团体集聚现 象, 这种子群结构不完全由空间距离决定, 还与生 态游憩空间的服务水平成正比,因此也可能存在个 别子群内部板块在空间上不连续的现象。凝聚子 群密度表征了连接度的大小

具体操作时, 首先建立以 $G_{a b}$ 值为指标的 $N \times N$ 的对称矩阵(表 3 ), 将矩阵导人UNINET 6.212, 再运 用 CONCOR算法揭示生态游㽞网络的凝聚子群。 CONCOR算法是一种迭代相关收敛法,它首先计算 出矩阵各行(或各列)的相关系数, 然后进一步计算 相关系数矩阵各行 (或各列)的相关系数, 经多次迭 代运算后,矩阵的相关系数值由 -1 和 1 组成, 对 -1 和 1 进行重新排列, 就得出了绿道连接的生态游憩 空间的凝聚子群分组结果(刘军, 2009)。

\section{2 分布模式与成因}

\section{1 连接度及其分布模式分析}

由绿道连接的拓扑网络(图 3)统计出连接数 $(L)$ 为 208 , 共贯通 198 个节点 $(V)$, 占生态游憩空间总数 的 $36.7 \%$, 连通面积为 20.84 万 $\mathrm{hm}^{2}$, 占总面积的 $39.4 \%$, 表明仍有大部分区域性生态游惒空间孤立 于省立绿道网络之外,特别是城市群边缘区孤立的 点较多。根据式(1)-(3)计算出 $\alpha$ 指数为 0 , 说明绿

表 2 各等级生态游憩空间的权重

Tab.2 Weights of ecological recreation spaces at all levels

\begin{tabular}{ccccc}
\hline 序号 & 景区等级 & 其他生态游䡯空间等级 & 权重值 & 游诱服务供给水平 \\
\hline 1 & AA & 县级 & 0.333 & 低 \\
2 & AAA & 市级 & 0.667 & 中 \\
3 & AAAA & 省级 & 1 & 高 \\
4 & AAAAA & 国家级 & 1.333 & 最高 \\
\hline
\end{tabular}

表 3 由 $G_{a b}$ 值建立的对称矩阵

Tab.3 Symmetric matrix based on the values of $\boldsymbol{G}_{a b}$

\begin{tabular}{|c|c|c|c|c|c|c|c|}
\hline & $\begin{array}{c}\text { 珠海尖峰山 } \\
\text { 森林公园 } \\
\end{array}$ & $\begin{array}{c}\text { 肇庆星湖 } \\
\text { 风景名胜区 }\end{array}$ & $\begin{array}{c}\text { 深圳梧桐山 } \\
\text { 国家森林公园 } \\
\end{array}$ & $\begin{array}{l}\text { 深圳大鹏半岛 } \\
\text { 国家地质公园 }\end{array}$ & $\begin{array}{c}\text { 广州海珠湖 } \\
\text { 国家湿地公园 }\end{array}$ & $\begin{array}{c}\text { 江门圭峰山 } \\
\text { 国家森林公园 }\end{array}$ & $\begin{array}{c}\text { 东莞松山 } \\
\text { 湖景区 } \\
\end{array}$ \\
\hline 珠海尖峰山森林公园 & 0 & & & & & & \\
\hline 肇庆星湖风景名胜区 & 7.830 & 0 & & & & & \\
\hline 深圳梧桐山国家森林公园 & 0.946 & 23.042 & 0 & & & & \\
\hline 深圳大鹏半岛国家地质公园 & 14.886 & 337.646 & 3205.033 & 0 & & & \\
\hline 广州海珠湖国家湿地公园 & 10.115 & 305.019 & 17.638 & 240.441 & 0 & & \\
\hline 江门圭峰山国家森林公园 & 24.799 & 571.241 & 32.56 & 494.311 & 517.999 & 0 & \\
\hline 东莞松山湖景区 & 10.142 & 266.339 & 1411.108 & 7039.627 & 221.418 & 362.243 & 0 \\
\hline
\end{tabular}


道网络的回路数趋近 0 。同样, 可计算出 $\beta$ 值为 $0.386, \gamma$ 指数等于 0.129 。 $\alpha 、 \beta$ 、指数均较小, 说明珠 三角城市群已经形成的生态游㮩空间网络为树状 网络, 孤点数多, 环通性较差, 总体连接度较低。

使用 ArcGIS 网络分析方法, 以绿道为连接线, 以生态游憩空间为节点, 建立 OD 成本矩阵, 得出节 点间的最短绿道长度, 在此基础上根据式(4)计算得 出 $G_{a b}$ 值, 再利用CONCOR算法得出生态游憩空间 集群的第 3 个层面有 8 个凝聚子群,在第 2 个层面又 进一步将 8 个子群归纳成 4 个子群。将子群编号作 为属性赋值给生态游憩空间,并进行空间制图分析。

图 4 显示的是第 2 个层面的 4 个子群分区结果， 根据其分布位置和范围可以将其命名为: (1) 珠三角 南部组团; (2) 珠三角东部组团; (3) 珠三角西部组 才; (4) 珠三角北部组团。说明绿道连接效应使珠三 角城市群生态游㮩空间分布形成四大联系相对紧

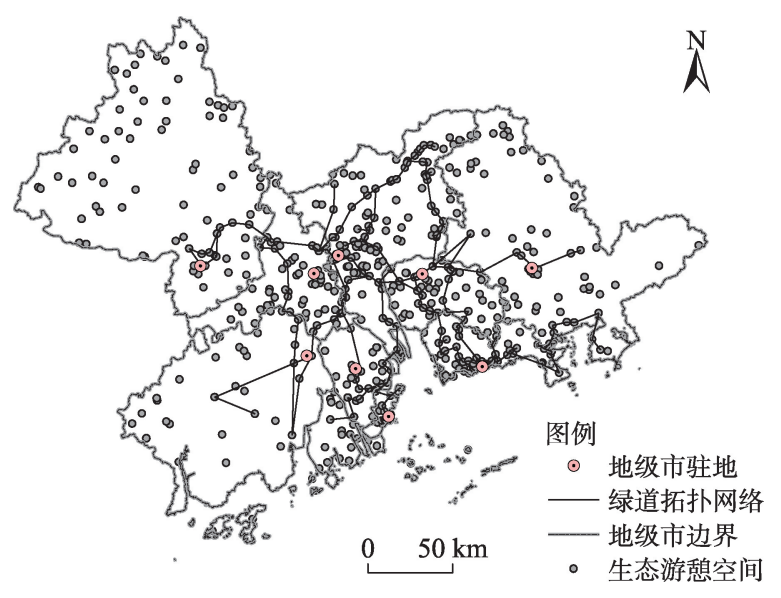

图 3 珠三角城市群区域绿道连接的拓扑网络

Fig.3 Topological network connected by greenways in the Pearl River Delta region

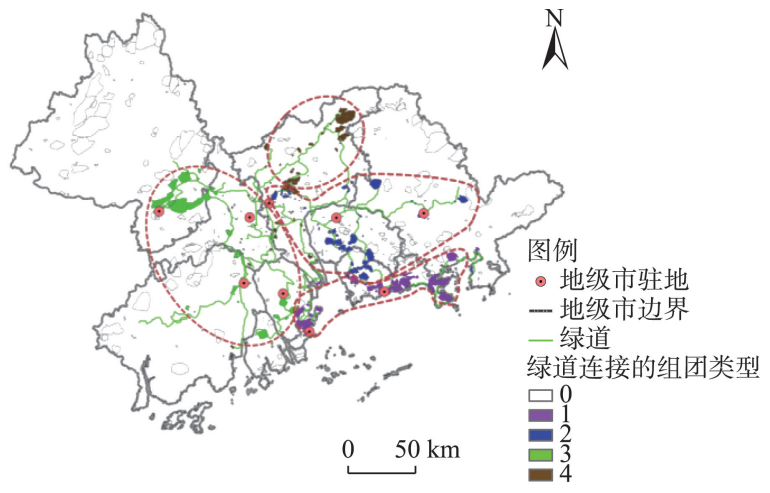

注:0表示绿道未连接的生态游惒空间。

图 4 第 2 个层面的 4 个子群的空间分布

Fig.4 Spatial distribution of the four subgroups at Level 2
密的片区。

图 5 显示的是第 3 个层面的 8 个凝聚子群: (1) 珠海市东部集群; (2) 深圳市东部一惠州市南部集 群; (3) 东莞市一深圳市北部一惠州市西部集群; (4) 深圳市西部和广州市中部集群; (5) 珠海市西部一中 山市南部集群; (6) 肇庆市市辖区一佛山市一江门市 东北部集群; (7) 广州市南部集群;8)广州市北部集 群。8个组团中,除了组团(4) 由空间不邻近的两部 分组成外,其余的都具有空间集聚性。

由凝聚密度表(表4)对角线上数据可知,在 8 个 子群中,第 $1 、 2 、 6$ 子群内部生态游唕空间的面积较 大,分布集中,因而密度值远高于其他子群。第 $4 、 8$ 子群内部成员面积也较大,但由于空间分布较分 散, 因此密度值处于中等水平。子群 3 内部的生态 游唕空间分布更分散,子群 5 的生态游唕空间数量 较少, 而子群 7 内的生态游憩空间面积小, 生态游憩 服务的供给水平较低, 因而东莞市-深圳市北部-惠 州市西部集群、珠海市西部-中山市南部集群、广州 市南部集群的密度值都偏低。

根据表 4 中子群之间密度值制作图 6, 进一步 发现子群 $1 、 3 、 4$ 和 8 之间的连接度高, 子群 $2 、 3 、 4$ 和 8 之间的连接度也相对较高。除子群 1 分布在珠江 河口西岸(但紧邻东岸子群)之外,其他的子群都分 布在珠三角河口的东岸和北部, 说明珠三角东部和 北部的广州、东莞、深圳、惠州以及珠海市东部 5 个 区域的生态游憩空间的连接度较好, 这不仅是由于 它们之间绿道网络相对完善, 也由于该范围内生态 空间的游㮩利用率较高。

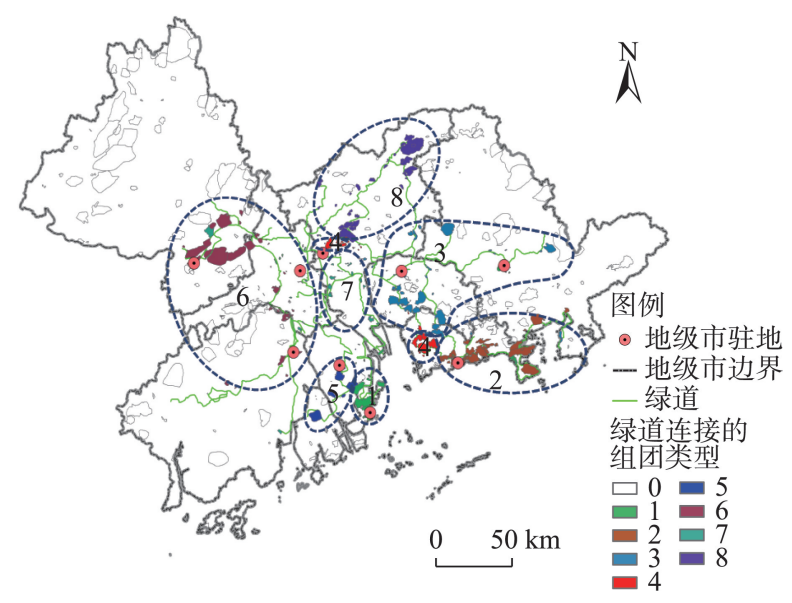

注:0 表示绿道未连接的生态游憩空间。

图 5 第 3 个层面的 8 个凝聚子群的分布

Fig.5 Spatial distribution of the eight cohesive subgroups at Level 3 
表 4 珠三角城市群生态游熄网络的凝聚子群密度

Tab.4 Cohesive subgroup density of the ecological recreation network of the Pearl River Delta urban agglomeration

\begin{tabular}{|c|c|c|c|c|c|c|c|c|}
\hline 名称 & 子群(1) & 子群(2) & 子群(3) & 子群(4) & 子群(5) & 子群(6) & 子群(7) & 子群(8) \\
\hline (1) 珠海市东部集群 & 25701.94 & & & & & & & \\
\hline (2) 深圳市东部-惠州市南部集群 & 46.94 & 6721995.50 & & & & & & \\
\hline (3) 东莞市-深圳市北部-惠州市西部集群 & 3266.27 & 79.88 & 984.72 & & & & & \\
\hline (4) 深圳市西部和广州市中部集群 & 37997.99 & 108.19 & 82.71 & 3310.63 & & & & \\
\hline (5) 珠海市西部-中山市南部集群 & 1.49 & 2.02 & 3.97 & 2.14 & 681.82 & & & \\
\hline (6) 肇庆市辖区-佛山市-江门市东北部集群 & 6.62 & 4.73 & 10.19 & 5.97 & 5.90 & 118111.57 & & \\
\hline (7) 广州市南部集群 & 1.85 & 0.95 & 2.33 & 1.57 & 9.25 & 5.44 & 56.26 & \\
\hline (8) 广州市北部集群 & 213.55 & 21.29 & 118.49 & 956.53 & 6.72 & 20.33 & 6.18 & 9250.32 \\
\hline
\end{tabular}

注: 斜体字为凝聚子群内部密度值, 其余数字为凝聚子群间的密度值。

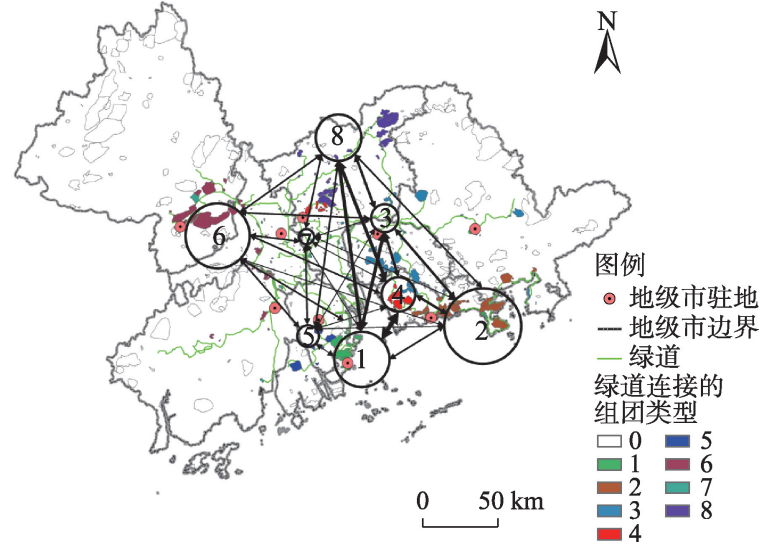

注: 本图根据表 4 绘制, 各编号代表的含义同表 4 ,密度值越 高,则箭头或圆圈的形状越大。

图 6 各凝聚子群间连接关系图示

Fig.6 Illustration of the connections between the cohesive subgroups

然而, 子群 1 和 5 尽管空间邻近, 但是彼此之间 的子群密度值仅为 1.49 , 说明二者的连接度不高, 这是因为 2 个子群之间缺少绿道连接, 导致二者彼 此孤立。子群 7 位于与子群 $3 、 5 、 6 、 8$ 联系的关键位 置, 但与周边子群的密度值均低于 10 , 说明其与周 边子群的空间联系不高, 未能起到应有的纽带作 用。此外, 子群 5、6、7 与外部子群之间的密度值普 遍偏低, 表明这 3 个子群相对孤立。从这些子群分 布的位置可以判断出珠三角城市群西南部的佛山 市、珠海市、中山市、江门市和西北部的肇庆市之间 连接度不高, 且西南部子群、西北部子群与北部、东 部子群之间的连接度也较低, 说明生态游惒空间连 接的空间分割性比较明显。

\section{2 成因解析}

2.2.1 绿道政策与布局

由于珠三角区域绿道目前主要分布在市辖区,
因此,城市群核心地区生态游憩空间成为了一个整 体, 连接度较高, 郊区市县绝大多数生态游敀空间 尽管规模相对较大,如肇庆市的西北部地区、江门 市的西部地区等, 却未能被纳人城市群生态开放空 间网络, 导致绿道连接的生态游喤空间规模偏低, 说明现阶段区域绿道政策的取向是以建设都市绿 道、优化连片建成区生态系统和人居环境为主,生 态绿道、郊野绿道建设力度不强。此外, 珠三角绿 道布局还具有 2 个明显特征: 其一,珠三角东部和北 部的广州、东莞、深圳、惠州四市间绿道网络相对完 善, 区域绿道长度占总长度的 $57.5 \%$, 因而生态游䟤 空间的连接度较好; 其二, 广州-东莞-深圳与广州中山-珠海作为珠三角区域发展的 2 条主轴,各分布 有 2 条绿道干线,数量上高于其他地区, 这使得广州 至珠海方向、广州至深圳方向的连接度较高。

\subsection{2 绿道建设机制}

由图 2 可发现各市绿道长度存在较大的差异。 绿道发展是珠三角区域自上而下发起的,但为减少 省政府的财政负担,绿道建设采用的是自下而上的 机制, 省级管理部门负责规划和业务指导, 各城市 分别成立了市级绿道领导小组, 将建设任务分解至 县区(或镇),建设资金由市级政府或县区(镇)政府 负担,也有的由两级政府共同分担(刘铮, 2017)。总 体而言,地方政府(市、县区与镇政府)自主负担绿道 建设与维护所需资金,但因为地方财政实力与政府 竞争意识不一, 如广州市黄埔区主动要求建设 40 $\mathrm{km}$ 省立绿道(广州市林业和园林局, 2010), 导致绿 道建设水平出现差异, 最终使得广州、深圳、佛山等 市的区域绿道实际建设里程较长, 连接度也相对较 高, 而西部、西北地区成为绿道建设的短板。

2.2.3 生态游㮩空间规模的集聚格局

以面积为属性,对生态游憩空间分布图进行核 
密度分析(图 7), 发现生态游憩空间规模主要集聚在 深圳东部、深圳西部、东莞中南部、广州北部、肇庆 西南部、肇庆东北部、江门西部 7 个区域。根据表 4 可知, 珠海市东部集群(第 1 子群)、深圳市东部-惠 州市南部集群(第2子群)、肇庆市市辖区一佛山市一 江门市东北部集群(第6子群)与广州市北部集群(第 8 子群)内部连接度较高, 而这四大区域中恰存在较 大的生态游憩空间面积集聚区, 特别是第 2 子群的 集聚态势最明显。也就是说, 绿道在贯通生态游憩 空间面积集聚区时更可能会产生连接度较高的子 群。广州市南部集群(第 7 子群)内部缺少生态游喤 空间分布, 因而内部绿道虽然较长, 但连接度反而 最低。当然, 东莞市-深圳市北部-惠州市西部集群 (第 3 集群)也包含了东莞市中南部集聚区, 但该区 与所属子群西部的惠州市中部生态游狉空间集聚 区距离较远,生态游㰾空间分布分散, 因而子群内 部连接度较低。

\subsection{4 地理阻隔与空间邻近性}

珠江河口对东西两岸的阻隔是绿道连接的障 碍, 在其影响下, 除南部的第 4 组团外, 总体上形成 东、西、北等分割性比较明显的组团式分布模式(图 4)。在大的组团框架下, 各凝聚子群间的连接度也 明显受到空间邻近性的影响。例如, 广州、东莞、深 圳、惠州四市及珠海东部地域邻近, 因而该范围内 生态游憩空间凝聚子群间的密度较高, 而西侧的珠 海市西部-中山市南部集群(第 5 子群)、肇庆市辖 区-佛山市-江门市东北部集群(第6子群)与北部、 东部子群之间的空间距离较远, 因而子群之间连接 度也较低。

\section{3 结论、讨论与优化路径}

\section{1 结论与讨论}

(1) 本文定义了一个“生态游憩空间一区域绿 道”拓扑网, 构建了连接度定量评价的模型。“生态 游㮩空间一区域绿道”拓扑网的构想源自道路拓扑 网, 但与之不同的是, 生态游㮩网络中节点不具备 枢纽功能, 因而节点的㿈疾对整体连接度的负效应 要低于道路网(高洁, 2010)。评价模型的测算结果 主要反映了连接度的整体水平和空间分布特征, 在 方法应用上有一定的创新, 但模型也具有一定的局 限性。首先, 本文表达的连接度, 实际上是一种基 于绿道连接线的生态游憩空间综合功能间的潜在

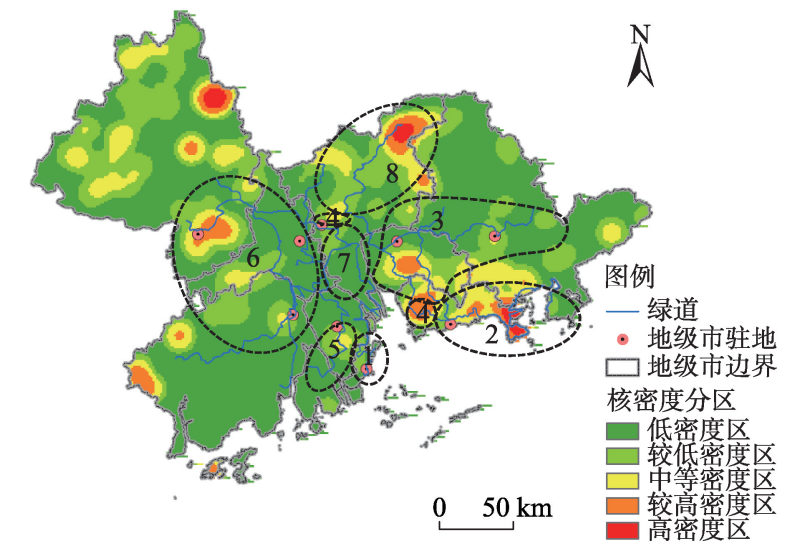

图 72017 年生态游憩空间规模分布的核密度

Fig.7 Nuclear density map of the scale of ecological recreation space in 2017

联系度, 侧重从景观形态与结构方面考察, 并不是 基于实际生态流、人流的各细分功能的联系。其 次, 模型对网络中边和节点的结构性特征缺少揭 示。实际上, 即使 2 个网络的边和节点数量相等, 也 会因为边连接方向不同导致总体连接度的差异。 最后,本文所用模型没能反映区域社会经济要素和 生态游憩空间连接度的关系。

(2) 本文采用 $\alpha 、 \beta 、 \gamma$ 指数评价了网络的回路数、 线点率和环通度, 发现珠三角城市群生态游㕷网络 为树状型, 节点数量、节点规模和回路数的值较低, 空间连接度整体不高。据测算, 绿道连接的节点数 量和面积不超过 $40 \%$, 仍有 $60 \%$ 以上的生态游敀空 间没有被纳人网络。由于珠三角区域绿道规划和 政策是以建成区优先, 然后再向郊区的乡村拓展, 因而郊区市县绝大多数生态游喤空间尽管规模相 对较大, 但未被接人绿道网,拉低了整体的连接 度。而城市群核心地区现有绿道网络也因为环线 和连接道较少, 所以环通度较差、总体连接度较 低。与道路网类似(徐军等, 2000), $\alpha$ 、 $\beta$ 、指数值主 要体现了生态游憩网络中边的数量多少, 但难以反 映网络在结构和形态方面的特性。

(3) “生态游憩空间-区域绿道”网络呈集群式 分布, 各集群连接度存在明显的区域分异。绿道分 布和生态游㰾空间规模集聚的双重效应使珠三角 城市群形成了 8 个凝聚子群, 且边缘地区子群(包括 第 $1 、 2 、 6 、 8$ 子群)的连接度要高于中心地区子群的 密度。这一结论与大都市区绿地的可达性格局 (Dai,2011)以及珠三角城市群生态游憩空间可达性 格局类似(Wang et al, 2018), 但与工业化和城镇化 
格局恰好相反, 这是由于中心地区人口、产业与城 镇等要素高度集聚, 占用了较多的生态空间(叶玉 瑶,2006; 丁俊等, 2016), 而边缘山区和海滨地区还 保留有规模较大的生态游憩空间, 表明了城镇化进 程中生态景观可持续发展和建设用地扩张的矛盾, 同时也凸显了通过区域绿道整合城市群中心区和 边缘区生态游憩空间的必要性。

(4) 生态游憩空间集群之间的空间联系呈现出 东部-北部大于西部、东西部之间空间分割性比较 明显的格局。具体而言, 珠三角东部-北部的广州、 东莞、深圳、惠州以及珠海市东部 5 个区域内的第 $1 、 2 、 3 、 4 、 8$ 子群之间连接度相对较高, 而珠三角城 市群西南部子群、西北部子群与东部-北部子群之 间的连接度较低, 空间分割性比较明显。这与陈浩 等(2011)得出的珠三角城市群旅游流联系、陈伟劲 等(2013)发现的城市联系的网络结构以及区域发展 轴线布局类似, 即由深圳、广州和珠海市构成的三 角形区域旅游流联系较密切, 并显著大于其他区 域。原因在于 3 个方面:一是因为绿道布局与旅游 流、城市联系和区域规划的空间轴线分布类似; 其 二, 生态游憩空间规模分布不平衡, 广州、深圳、东 莞城市经济发展和城镇化水平高, 生态游憩空间建 设力度更大,集聚水平要大于西部地区(图 7); 其三, 东部-北部之间的子群分布邻近, 而与西部子群则 距离相对较远, 且受珠江河口阻隔。这说明各地市 绿道建设和生态空间游憩利用各自为阵, 协作力度 不够,而区域所做的统筹协调工作也不够。

\section{2 优化路径}

优化“生态游喤空间-区域绿道”网络是完善区 域生态开放空间系统的基本路径, 具有重要的战略 意义。研究结论启示未来城市群要以网络化思维 整合城区和郊区 “生态游唕空间-绿道”系统, 优化 绿道连接的拓扑结构, 形成完善的区域生态游憩 网络。

3.2.1 推进城市群边缘区生态游憩空间的绿道连接 充分借鉴欧美国家绿道建设的经验, 实现绿道 与生态游唕空间的穿点连线、集结成网、互联互 通。如美国绿道建设注重利用绿道连接郊区的郊 野公园、区域公园、国家公园以及其他自然保留地, 形成一个相互连通的生态游敀空间网络, 既增加了 开敞空间,也促进了生态系统的完整性保护。珠三 角城市群边缘区的不少生态游喤空间是未被绿道 连接的“孤岛”, 不利于从整体上提升生态系统服
务。建议城市群对河流、山谷等生态廊道以及交通 线两侧生态环境进行整治和修复,开辟绿道开敞空 间,将绿道网向城市群边缘区延伸, 同时增设郊区 绿道环线, 将全域主要生态游憩空间连接起来, 完 善生态网络, 控制城市蔓延, 也有助于增加居民的 郊野游憩机会, 带动城郊旅游业发展, 深人推进城 乡一体化。

\subsection{2 完善城市群现有绿道连接网络}

绿道连接的生态游憩空间拓扑网络的 $\alpha 、 \beta 、 \gamma$ 指 数较小, 说明网络的连接度不高, 环通性差, 且除了 少数几个凝聚子群与其他子群间密度较高外, 大部 分子群之间的密度偏低, 说明它们之间的空间联系 不强。下一步需要完善区域绿道网来优化生态游 憩网络, 其中一项重要工作是加强区域绿道环线建 设, 优化内部衔接, 提升城市群生态游憩空间的连 续性和互通性。例如, 如果在凝聚子群 1 和子群 5 之间有绿道连接, 二者有望成一个整体, 而不再是 2 个分割的子群; 此外,大部分区域绿道为“断头路”, 可以因地制宜地建设环线连接绿道末端, 构成环线 型生态廊道, 增加环通度。

\subsection{3 加强生态空间修复与游㮩利用}

研究结果显示: 大部分子群密度值较低, 与其 内部生态游憩空间节点数、节点规模和等级状况有 关。要提升子群连接度, 首先需要依据生态适宜性 进一步促进城市群现有生态空间的游憩利用,增加 连接的节点数; 其次, 利用生态修复扩展生态游㰾 空间数量和规模。例如,广州市南部集群(第 7 子 群)属于建成区, 生态游惒空间稀缺(图 7), 应通过城 市更新、人口疏散以及生态修复等综合治理手段, 增加生态游憩空间供给, 充分彰显其枢纽型节点的 作用; 最后, 通过提升生态游喤空间节点的生态景 观与游憩服务质量, 提升节点等级, 从而加强节点 之间互动强度。

3.2.4 建立绿道建设和生态空间游㮩利用的区域统 筹机制

自下而上的绿道建设和生态空间游憩开发运 动,在短期内取得了一定的效果,但行政区间协调 性不强, 且可持续性较差。为此, 珠三角城市群生 态游憩空间与区域绿道的空间整合,应该实行自下 而上和自上而下相结合的路径, 加强顶层设计与统 筹协调力度, 加强区域一体化的制度和组织设计, 在区域绿道和生态游憩空间顶层规划和建设时考 虑行政区间的衔接和平衡。在项目建设机制上可 
以以地方建设为主, 以区域性开发作为补充。例 如, 可以设立区域生态开放空间投资建设开发公 司, 吸收各地方政府、企业等作为投资主体, 搭建生 态游㰾空间和绿道项目建设与经营的统一平台, 统 筹优化城市群生态景观的游惒化利用格局。

\subsection{5 强化 “生态游惒空间-区域绿道”规划与优化 的科技支撑}

需进一步加强 “生态游㮩空间-区域绿道”网络 评估和规划的理论和技术方法研究, 为绿道与生态 游㓤空间的科学布局与管理提供更有力的决策支 持。本文虽就此进行了有益探究, 但仍需突破的问 题包括: (1) 珠三角城市群部分绿道段存在配套设施 不完善、生态性不足、过于人工化与交通化等问题 (胡卫华, 2013; 刘铮, 2017), 后续研究需重视绿道设 计、建设和管理中的微观问题, 加强中观微观尺度 绿道质量和功能评价与实证研究, 为绿道设计和建 设提供支撑; (2) 进一步加强方法和技术手段的创 新, 力争利用实际对流数据来考察生态游憩空间细 分功能的连接度,刻画网络在结构上的特性; (3) 引 人社会经济要素, 基于多要素间关系综合评价网络 的文化服务功能, 如考察人口对网络的可达性, 调 研居民对网络的感知、评价、使用行为以及网络对 身心健康、社会融合等的效应, 为网络的管理提供 支撑。

\section{参考文献(References)}

查尔斯·E・利特尔. 2013. 美国绿道 $[\mathrm{M}]$. 余青, 莫雯静, 陈海

沐, 译. 北京: 中国建筑工业出版社. [Little C E. 2013. American greenways. Translated by Yu Q, Mo W J, Chen H M. Beijing, China: China Building Industry Press. ] 柴舟跃, 谢晓萍, 尤利安・韦克尔. 2016. 德国城市群内区域公 园规划管理手段研究: 以莱茵美茵区域公园为例 [J]. 国 际城市规划, 31(2): 110-115. [Chai Z Y, Xie X P, Wekel J. 2016. Research on planning and management of regional parks in german metropolitan regions: A case study on Regional Park Rhein Main in Frankfurt/Rhein-Main metropolitan region. Urban Planning International, 31(2): 110-115. ]

陈浩, 陆林, 郑嬗婷. 2011. 基于旅游流的城市群旅游地旅游 空间网络结构分析: 以珠江三角洲城市群为例 [J]. 地理 学报, 66(2): 257-266. [Chen H, Lu L, Zheng S T. 2011. The spatial network structure of the tourism destinations in urban agglomerations based on tourist flow: A case study of the Pearl River Delta. Acta Geographica Sinica, 66(2): 257-266. ]

陈爽, 王丹, 王进. 2010. 城市绿地服务功能的居民认知度研
究 [J]. 人文地理, 25(4): 55-59. [Chen S, Wang D, Wang J. 2010. A study on greenspace service cognition of urban residents in Nanjing China. Human Geography, 25(4): 5559. ]

陈伟劲, 马学广, 蔡莉丽, 等. 2013. 珠三角城市联系的空间 格局特征研究: 基于城际客运交通流的分析 [J]. 经济地 理, 33(4): 48-55. [Chen W J, Ma X G, Cai L L, et al. 2013. Characteristics of regional city connection's spatial pattern based on intercity passenger traffic flow in Pearl River Delta. Economic Geography, 33(4): 48-55. ]

丁俊, 王开泳. 2016. 珠江三角洲城市群工业生产空间格局、 形态特征及影响因素 [J]. 地理科学进展, 35(5): 610-621. [Ding J, Wang K Y. 2016. Spatial pattern and morphological characteristics of industrial production space and influential factors in the Pearl River Delta urban agglomeration. Progress in Geography, 35(5): 610-621. ]

冯利芳. 2012. 功在当下造福千秋: 珠三角绿道网建设的调 查报告 [J]. 城市发展研究, 19(2): 1-6. [Feng L F. 2012. Investigating on the Pearl River Delta greenway network. Urban Studies, 19(2): 1-6. ]

佛山市人民政府. 2017. 佛山市城市生态控制线划定规划 [EB/OL]. (2017-06-20)[2018-04-04]. http://www.fs.gov.cn/ zwgk/zfgb/rmzfbgshj/201706/t20170623_6247348.html.

[The People's Government of Foshan City. 2017. Planning of urban ecological control line in Foshan City. (2017-0620) [2018-04-04]. http://www.fs.gov.cn/zwgk/zfgb/rmzfbgshj/201706/t20170623_6247348.html. ]

富伟, 刘世梁, 崔保山, 等. 2009. 景观生态学中生态连接度 研究进展 [J]. 生态学报, 29(11): 6174-6182. [Fu W, Liu S L, Cui B S, et al. 2009. A review on ecological connectivity in landscape ecology. Acta Ecologica Sinica, 29(11): 6174-6182. ]

高长征, 王成晖, 宋亚亭. 2011. 珠三角区域绿道建设与管理 问题研究 [J]. 规划师, 27(S1): 153-158. [Gao C Z, Wang C H, Song Y T. 2011. Greenbell construct and management of Pearl River Delta. Planner, 27(S1): 153-158. ]

高洁. 2010. 交通运输网络连通性评价指标分析 [J]. 交通运 输工程与信息学报, 8(1): 35-38. [Gao J. 2010. Analysis of transportation network connectivity evaluation index. Journal of Transportation Engineering and Information, 8(1): 35-38. ]

广东省旅游局. 2017. 广东省 $\mathrm{A}$ 级旅游景区名录(截至 2017 年 9 月 8 日) [EB/OL]. (2017-10-30) [2018-01-01]. http:/ zwgk.gd.gov.cn/006940247/201710/t20171024_727479.ht ml. [Tourism Bureau of Guangdong Province. A list of grade- A scenic spots in Guangdong Province (up to September 8, 2017). (2017-10-30) [2018-01-01]. http://zwgk. gd.gov.cn/006940247/201710/t20171024_727479.html. ] 
广东省住房和建设厅. 2010. 珠江三角洲绿道网总体规划纲 要 [J]. 建筑监督检测与造价, (3): 10-70. [Department of Housing and Urban-rural Of Guangdong Province. 2010. Green Pearl River Delta road network master plan outline. Supervision Test and Cost of Construction, (3): 10-70. ]

广州市林业和园林局. 2010. 广州市绿道网建设第四次现场 会议 [R]. 广州: 广州市林业和园林局. [Guangzhou Forestry and Landscape Bureau. 2010. The fourth on- site meeting of Guangzhou greenway network construction. Guangzhou, China: Guangzhou Forestry and Landscape Bureau. ]

胡卫华. 2013. 绿道旅游存在的问题及开发对策: 以珠三角 绿道网为例 [J]. 热带地理, 33(4): 504-510. [Hu W H. 2013. Problems of greenway tourism and countermeasures: A case study of PRD. Tropical Geography, 33(4): 504-510. ]

李华. 2015. 城市生态游悡空间服务功能评价与优化对策 [J]. 城市规划, (8): 63-69. [Li H. 2015. Evaluation and optimization countermeasures for service functions of urban ecological recreation space. City Planning Review, (8): 6369. ]

李玏, 刘家明, 宋涛, 等. 2015. 北京市绿带游㮩空间分布特 征及其成因 [J]. 地理研究, 34(8): 1507-1521. [Li L, Liu J M, Song T, et al. 2015. Spatial characteristics and causes of recreational space in the urban green belt of Beijing, China. Geographical Research, 34(8): 1507-1521. ]

刘军. 2009. 整体网分析讲义: UCINET 软件实用指南 [M]. 上海: 格致出版社. [Liu J. 2009. Lectures on whole network approach: A practical guide to UCINET. Shanghai, China: Gezhi Press. ]

刘岳, 李忠武, 唐政洪, 等. 2012. 基于适宜性分析与 GIS 的长 沙市大河西先导区城市绿道网络设计 [J]. 生态学杂志, 31(2): 426-432. [Liu Y, Li Z W, Tang Z H, et al. 2012. Greenway network design of Great West River Pilot Area in Changsha City, Hunan Province of South- central China based on suitability analysis and GIS. Chinese Journal of Ecology, 31(2): 426-432. ]

刘铮. 2017. 都市主义转型: 珠三角绿道的规划与实施 [D]. 广州: 华南理工大学. [Liu Z. 2017. Urbanism in transformation: The planning and implementation of the Pearl River Delta greenways. Guangzhou, China: South China University of Technology. ]

卢飞红, 尹海伟, 孔繁花. 2015. 城市绿道的使用特征与满意 度研究: 以南京环紫金山绿道为例 [J]. 中国园林, 31(9): 50-54. [Lu F H, Yin H W, Kong F H. 2015. The using characteristics and satisfaction of urban greenway: A case study of the purple mountain greenway in Nanjing. Chinese Landscape Architecture, 31(9): 50-54. ]
马向明, 程红宁. 2013. 广东绿道体系的构建: 构思与创新 [J]. 城市规划, 37(2): 38-44. [Ma X M, Cheng H N. 2013. Building of greenway system in Guangdong Province: Conception and innovation. City Planning Review, 37(2): 38-44. ]

马向明, 杨庆东. 2017. 广东绿道的两个走向: 南粤古驿道的 活化利用对广东绿道发展的意义 [J]. 南方建筑, (6): 4448. [Ma X M, Yang Q D. 2017. Two trends of Guangdong greenway system evolution: The significance of the revitalization of South China historical trail to Guangdong greenway system. South Architecture, (6): 44-48. ]

孙琨, 唐承财, 钟林生. 2016. 基于人口特征的城市生态游悡 空间配置: 以常熟市为例 [J]. 地理科学进展, 35(6): 714723. [Sun K, Tang C C, Zhong L S. Siting of urban recreational eco-space based on population characteristics: A case study of Changshu City, China. Progress in Geography, 35(6): 714-723. ]

孙琨, 钟林生, 张爱平, 等. 2016. 城市生态游㕰空间休闲价 值对比分析: 以常熟市为例 [J]. 地理研究, 35(2): 256270. [Sun K, Zhong L S, Zhang A P, et al. 2016. Comparative analysis on the leisure values of urban ecological recreation spaces: A case study of Changshu City. Geographical Research, 35(2): 256-270. ]

文克・ E・德拉姆施塔德, 温迪・J 杰里施塔德, 徐凌云, 等. 2016. 景观生态学作为可持续景观规划的框架 [J]. 中国 园林, 32(4): 16-27. [Wenche E. DRAMSTAD, Wendy J. FJELLSTAD, Xu L Y. 2016. Landscape ecology as a framework for sustainable landscape planning. Chinese Landscape Architecture, 32(4): 16-27. ]

吴隽宇, 游亚昀. 2017. 珠三角区域绿道(省立)一号线生态系 统服务功能价值评估研究 [J]. 中国园林, 33(3): 98-103. [Wu J Y, You Y Y. 2017. Preliminary assessment of ecosystem services value of Pearl River Delta greenway line one. Chinese Landscape Architecture, 33(3): 98-103. ]

熊春妮, 魏虹, 兰明娟. 2008. 重庆市都市区绿地景观的连通 性 [J]. 生态学报, 28(5): 2237-2244. [Xiong C N, Wei H, Lan M J. 2008. Analysis of connectivity on greenland landscape in metropolitan region of Chongqing City. Acta Ecologica Sinica, 28(5): 2237-2244. ]

徐东辉, 郭建华, 高否. 2014. 美国绿道的规划建设策略与管 理维护机制 [J]. 国际城市规划, 29(3): 83-90. [Xu D H, Guo J H, Gao L. The planning \& construction strategy and management \& maintenance mechanism of American greenway. Urban Planning International, 29(3): 83-90. ]

徐军, 罗嵩龄. 2000. 公路网连通性研究 [J]. 中国公路学报, 13(1): 95-97. [Xu J, Luo S L. A study of connectness for the highway network. China Journal of Highway and Transport, 13(1): 95-97. ] 
杨丽婷, 刘大均, 赵越, 等. 2016. 长江中游城市群森林公园 空间分布格局及可达性评价 [J]. 长江流域资源与环境, 25(8): 1228-1237. [Yang L T, Liu D J, Zhao Y, et al. 2016. Spatial pattern and accessibility of the forest parks in urban agglomeration in the middle reaches of the Yangtze River. Resources and Environment in the Yangtze Basin, 25 (8): 1228-1237. ]

叶盛东. 1992. 美国绿道简介 [J]. 国外城市规划, (3): 46-49. [Ye S D. 1992. The introduction of American greenways. Urban Planning International, (3): 46-49. ]

叶玉瑶. 2006. 城市群空间演化动力机制初探: 以珠江三角 洲城市群为例 [J]. 城市规划, 30(1): 61-66. [Ye Y Y. 2006. Spatial evolution mechanism of urban conglomeration: A case study of the Pearl River Delta. City Planning Review, 30(1): 61-66. ]

殷柏慧, 吴必虎. 2004. 长三角与环渤海区域旅游合作条件 对比研究: 兼论环渤海次区域旅游合作道路选择 [J]. 旅 游学刊, 19(6): 33-37. [Yin B H, Wu B H. 2004. A comparative study on regional tourism cooperation between Yangtze River Delta and Bohai Rim. Tourism Tribune, 19(6): 33-37. ]

俞孔坚, 李伟, 李迪华, 等. 2005. 快速城市化地区遗产廊道 适宜性分析方法探讨: 以台州市为例 [J]. 地理研究, 24 (1): 69-76. [Yu K J, Li W, Li D H. 2005. Suitability analysis of heritage corridor in rapidly urbanizing region: A case study of Taizhou City. Geographical Research, 24(1): 6976. ]

赵珂, 李享, 袁南华. 2017. 从美国“绿道”到欧洲绿道: 城乡 空间生态网络构建: 以广州市增城区为例 [J]. 中国园林, 33(8): 82-87. [Zhao K, Li X, Yuan N H. 2017. From American "Greenway" to European Greenway: The construction of ecological network in urban and rural space: A case study of Zengcheng District of Guangzhou. Chinese Landscape Architecture, 33(8): 82-87. ]

周年兴, 俞孔坚, 黄震方. 2006. 绿道及其研究进展 [J]. 生态 学报, 26(9): 3108-3116. [Zhou N X, Yu K J, Huang Z F. 2006. Perspectives on greenway development. Acta Ecologica Sinica, 26(9): 3108-3116. ]

Ahern J. 1995. Greenways as a planning strategy [J]. Landscape and Urban Planning, 33 (1-3): 131-155.

Akpinar A. 2016. Factors influencing the use of urban greenways: A case study of Aydın, Turkey [J]. Urban Forestry \& Urban Greening, 16: 123-131.

Arnberger A, Eder R. 2012. The influence of green space on community attachment of urban and suburban residents [J]. Urban Forestry \& Urban Greening, 11(1): 41-49.

Cook E A. 2002. Landscape structure indices for assessing urban ecological networks [J]. Landscape and Urban Plan- ning, 58(2-4): 269-280.

Czembrowski P, Kronenberg J. 2016. Hedonic pricing and different urban green space types and sizes: Insights into the discussion on valuing ecosystem services [J]. Landscape and Urban Planning, 146: 11-19.

Dai D. 2011. Racial/ethnic and socioeconomic disparities in urban green space accessibility: Where to intervene? [J]. Landscape and Urban Planning, 102(4): 234-244.

Deenihan G, Caulfield B, O'Dwyer D. 2013. Measuring the success of the Great Western Greenway in Ireland [J]. Tourism Management Perspectives, 7: 73-82.

Dzhambov A M, Dimitrova D D. 2015. Green spaces and environmental noise perception [J]. Urban Forestry \& Urban Greening, 14(4): 1000-1008.

Fábos J G. 2004. Greenway planning in the United States: Its origins and recent case studies [J]. Landscape \& Urban Planning, 68(2): 321-342.

Flink C A, Olka K, Searns R M. 2001. Trails for the Twentyfirst Century: Planning, Design, and management manual for multi-use trails $[\mathrm{M}]$. Second Edition. Washington: Island Press

Jang M, Kang C-D. 2015. Urban greenway and compact land use development: A multilevel assessment in Seoul, South Korea [J]. Landscape and Urban Planning, 143: 160-172.

Keith S J, Larson L R, Shafer C S, et al. 2018. Greenway use and preferences in diverse urban communities: Implications for trail design and management [J]. Landscape and Urban Planning, 172: 47-59.

Linehan J, Gross M, Finn J. 1995. Greenway planning: Developing a landscape ecological network approach [J]. Landscape \& Urban Planning, 33(1-3): 179-193.

Madureira H, Nunes F, Oliveira J V, et al. 2015. Urban residents' beliefs concerning green space benefits in four cities in France and Portugal [J]. Urban Forestry \& Urban Greening, 14(1): 56-64.

Preston- Whyte R. 2001. Constructed leisure space: The seaside at Durban [J]. Annals of Tourism Research, 28(3): 581-596.

Rao P S, Gavane A G, Ansari M F, et al. 2004. Performance evaluation of a green belt in a petroleum refinery: A case study [J]. Ecological Engineering, 23(2): 77-84.

Senes G, Rovelli R, Bertoni D, et al. 2017. Factors influencing greenways use: Definition of a method for estimation in the Italian context [J]. Journal of Transport Geography, 65: 175-187.

Sinclair K E, Hess G R, Moorman C E, et al. 2005. Mammalian nest predators respond to greenway width, landscape context and habitat structure $[\mathrm{J}]$. Landscape and Urban 
Planning, 71(2-4): 277-293.

Smyth R, Mishra V, Qian X. 2008. The environment and wellbeing in urban China [J]. Ecological Economics, 68(1-2): $547-555$

Toccolini A, Fumagalli N, Senes G. 2006. Greenways planning in Italy: The Lambro River Valley Greenways System [J]. Landscape and Urban Planning, 76(1-4): 98-111.

Turner T. 2006. Greenway planning in Britain: Recent work and future plans $[\mathrm{J}]$. Landscape and Urban Planning, 76(14): 240-251.

Tyrväinen L, Mäkinen K, Schipperijn J. 2007. Tools for mapping social values of urban woodlands and other green areas [J]. Landscape and Urban Planning, 79(1): 5-19.
Wan C, Shen G Q. 2015. Encouraging the use of urban green space: The mediating role of attitude, perceived usefulness and perceived behavioural control $[\mathrm{J}]$. Habitat International, 50: 130-139.

Wang F Y, Wang K Y. 2018. Measuring spatial accessibility to ecological recreation spaces in the Pearl River Delta region: An improved twostep floating catchment area method [J]. Journal of Spatial Science, 63(2): 279-295.

Wasserman S, Faust K. 1994. Social network analysis: Methods and applications [M]. New York: Cambridge University Press.

Yu K, Li D, Li N. 2006. The evolution of greenways in China [J]. Landscape and Urban Planning, 76(1-4): 223-239.

\title{
Connectivity and distribution pattern of regional greenways and ecological recreation spaces in the Pearl River Delta urban agglomeration
}

\author{
WANG Fuyuan ${ }^{1,2}$, WANG Kaiyong ${ }^{1,2^{*}}$ \\ (1. Institute of Geographic Sciences and Natural Resources Research, CAS, Beijing 100101, China; \\ 2. Key Laboratory of Regional Sustainable Development Modeling, CAS, Beijing 100101, China)
}

\begin{abstract}
Greenways play an important role in building a continuous ecological open space system in an urban agglomeration. Based on the regional greenways in the Pearl River Delta urban agglomeration, topological network analysis and social network analysis were used to assess the connectivity and distribution pattern of ecological recreation space-regional greenway network. The results show that: 1) The $\alpha, \beta$, and $\gamma$ indices are 0 , 0.386 , and 0.129 respectively, indicating a low-circuitry and low-connectivity topological structure of the network. 2) The network is clustered, and the degree of connectivity of the cohesive subgroups at the edge is higher than that of the central region. 3) The degree of connectivity between the cohesive subgroups in the eastern and northern regions is greater than that of the cohesive subgroups in the western region, and the connectivity between the western subgroups and eastern subgroups is low, suggesting that the network is fragmented in the east- west direction. 4) The distribution pattern of the connectivity is formed under the influences of the greenway development policy and layout, the greenway construction mechanism, the agglomeration pattern of ecological recreation spaces, geographical barriers, and spatial proximity. Several pathways were proposed to construct an ecological recreation space-greenway network with higher connectivity, for providing some references for the planning and development of China's urban agglomerations.
\end{abstract}

Keywords: ecological recreation spaces; greenway; connectivity; distribution pattern; Pearl River Delta urban agglomeration 